\title{
Developing Methodologies for Predicting Sensitization to Formaldehyde in Adolescents
}

\author{
Liudmila B. Masnavieva \\ Department of Clinical and Experimental Researches \\ FSBSI "East-Siberian Institute of Medical and Ecological \\ Researches" \\ Angarsk, Russia \\ E-mail: Masnavieva_Luda@mail.ru \\ Olga A. Dyakovich \\ Department of Clinical and Experimental Researches \\ FSBSI "East-Siberian Institute of Medical and Ecological \\ Researches" \\ Angarsk, Russia \\ Salim F. Shajahmetov \\ Department of Management \\ FSBSI "East-Siberian Institute of Medical and Ecological \\ Researches" \\ Angarsk, Russia
}

\begin{abstract}
The study included 153 adolescents from the industrial city of air pollution formaldehyde environment. On the basis of immunological and hematological parameters adolescents developed mathematical formulas to predict organism sensitization of adolescents to formaldehyde without applying test reaction inhibition of leukocyte migration.
\end{abstract}

Keywords-adolescents; sensitization; formaldehyde; predicting method; autoantibody

\section{INTRODUCTION}

In recent decades, for the prediction and diagnosis of various diseases widely used mathematical approaches. This is due to the fact that the use of various diagnostic and prognostic algorithms makes it possible to set patterns for any disease or health state. One of the main principles of diagnostics is to strive to obtain the maximum of information in a limited amount of research. Currently in the field of biomedical modeling and forecasting the greatest number of studies devoted to the outcome of the disease course. At the same time, are quite relevant questions examine the relationship between different indicators relating to health or the course of the pathological process and allows for prediction of disease at the stage of screening.

To date remains poorly understood issues of environmental pollutants prediction of sensitization in adolescents with the

\author{
Irina V. Kudaeva \\ Department of Clinical and Experimental Researches \\ FSBSI "East-Siberian Institute of Medical and Ecological \\ Researches" \\ Angarsk, Russia
}

\author{
Viktor S. Rukavishnikov \\ Department of Management \\ FSBSI "East-Siberian Institute of Medical and Ecological \\ Researches" \\ Angarsk, Russia \\ Olga V. Popkova \\ Department of Clinical and Experimental Researches \\ FSBSI "East-Siberian Institute of Medical and Ecological \\ Researches" \\ Angarsk, Russia
}

help of mathematical methods. The value of such research depends on several factors. First of all, the fact that the child and adolescent population is one of the sensitive groups of influence of environmental factors because detoxification system and adaptive mechanisms they still are immature. In addition, adolescence is related to one of the critical periods of the formation of the immune system in ontogenesis, and therefore the impact on them of exogenous factors can affect the process of its formation $[1,2]$.

The most common disorders of the immune system, which in Russia is suffering one in four is allergy. And in the industrial cities and environmentally disadvantaged regions this figure is more than twice as high $[3,4,5]$. It should be noted that in recent years there has been a significant increase in the incidence of allergy intolerance to various chemicals, including quite inert [6].

This fact is connected, including the large-scale pollution of the environment by industrial enterprises with various chemical compounds $[7,8,9,10,11]$. One of the pollutants, present in large quantities in the atmosphere, formaldehyde is the main source of which is considered the chemical, petrochemical, woodworking and pulp and paper industries as well as construction, thermal insulation, decoration materials and furniture $[12,13]$. According to the degree of danger effects on the body formaldehyde include highly dangerous 
chemicals (2 class of danger). He has a general toxic, sensitizing and allergenic effects on the body.

In this connection, great importance is the timely detection of signs of toxicant exposure on children's and teenage body. One of the few methods of diagnosis sensitization refers to chemical compounds leukocyte migration inhibition test (LMIT) [14]. This test is a highly informative, however, the labor intensity, the need for a procedure under sterile conditions in the coming hours after blood collection do not allow to apply them by screening. In this regard, the search for alternative methods of diagnosis of sensitization to various substances, including the application of mathematical modeling is one of the urgent tasks of preventive medicine.

The objective of this study was to develop a mathematical model to predict sensitization to formaldehyde, using data on the levels of specific autoantibodies and parameters of leukocyte formula.

\section{MATERIALS AND METHODS}

The study involved 153 adolescents 14-17 years old from the industrial city living and attending educational institutions in areas with high levels of air pollution. Blood sampling was carried out in surveyed from the cubital vein using vacuum systems after a 12-hour fast. In the blood serum was investigated the relative abundance of specific autoantibodies (autoantibodies) class IgG to 16 different antigens, characterizing the state of the main organs and systems, semiquantitative enzyme immunoassay using the children's panel ELI-Viscera-Test-16 ("Immunculus", Moscow). In accordance with the instructions of the manufacturer of the test system was calculated the average individual immunoreactivity (AII) on the content of all the 16 specific autoantibodies and abnormality of the contents of each type of autoantibodies. The values of the relative content of autoantibodies can be both positive and negative [15].

For LMIT have been used leukocytes obtained from whole blood, taken with anticoagulant $\mathrm{K}_{3}$ EDTA. Leukocyte migration inhibition test was performed using Costar plates in RPMI1640 culture medium supplemented with the test chemokinetic factors (formaldehyde). It was used as a negative control culture medium without addition of chemoattractants. It was used mitogen phytohemagglutinin (PHA) as a positive control for inhibition of leukocyte migration. After incubation, the visually determined the size of the colony on the scale inside the eyepiece binocular magnifier. Migration index was calculated by the ratio of the test sample to a positive control. Migration indices lying outside $0,80-1,20$, is considered positive.

In the whole blood was investigated cell composition with differential leukocyte count conventional manner per 100 cells, expressed as \%.

To develop a method from surveyed were formed two "training" groups. Teenagers having an index inhibition migration of leukocytes to formaldehyde outside the reference values were the group I $(n=42)$, high school students with an index inhibition of migration of leukocytes in the normal range - group II $(\mathrm{n}=50)$. Statistical processing of results was performed with the help of «Statistica 6.0» application package of nonparametric methods (U-Mann-Whitney). The research results are presented as medians and interquartile range $(\mathrm{Me}$ (LQ-UQ)). For the development of the mathematical model used logistic regression method.

\section{RESULTS AND DISCUSSIONS}

Analysis of immunological and hematological studies in schoolchildren showed informative indicators that may indicate the presence of sensitization and be used to construct a mathematical model predicting sensitization of the organism adolescents to formaldehyde (Table 1.).

TABLE 1 INFORMATIVE IMMUNOLOGICAL AND HEMATOLOGICAL PARAMETERS IN ADOLESCENTS WITH LEUKOCYTE REACTION TO FORMALDEHYDE

\begin{tabular}{|c|c|c|c|}
\hline Parameters & Me & $\mathbf{Q 2 5}$ & Q75 \\
\hline \multicolumn{4}{|c|}{$\begin{array}{l}\text { Group of children with lack of response to formaldehyde } \\
\text { (an index of migration of leukocytes in the range of 0.8-1.2) }\end{array}$} \\
\hline Eosinophils, \%. & 2.00 & 1.00 & 3.50 \\
\hline $\begin{array}{l}\text { Autoantibodies to membrane antigens } \\
\text { lung parenchyma (auto-AT LuM), \% }\end{array}$ & -17.91 & -34.47 & -5.90 \\
\hline $\begin{array}{l}\text { Autoantibodies to beta2-glycoprotein } \\
\text { I } \beta 2 \text {-GP I ( } \beta 2 \text {-GP I), \% }\end{array}$ & 1.75 & -7.41 & 15.26 \\
\hline \multicolumn{4}{|c|}{$\begin{array}{l}\text { Group of children with existence of response to formaldehyde } \\
\text { (index of migration of leukocytes more than } 1.2 \text { or less than } 0.8 \text { ) }\end{array}$} \\
\hline Eosinophils, \% & 0.00 & 0.00 & 4.00 \\
\hline $\begin{array}{l}\text { Autoantibodies to membrane antigens } \\
\text { lung parenchyma (auto-AT LuM), } \%\end{array}$ & 119.19 & 46.32 & 479.94 \\
\hline $\begin{array}{l}\text { Autoantibodies to beta2-glycoprotein } \\
\text { I ( } \beta 2 \text {-GPI), \% }\end{array}$ & 1.17 & 26.66 & 3.77 \\
\hline
\end{tabular}

The next step is using logistic regression results of the research groups studied, we got two equations expressing the relationship of the variable (response to formaldehyde LMIT) the indicators are considered as predictors. For the first equation as predictors was used of eosinophils in the blood (EPZs) and the relative level of autoantibodies (autoAB) to membrane antigens of lung parenchyma (Lum). In the second equation predictors were the relative content of autoantibodies LuM and autoAB to $\beta 2$-glycoprotein I ( $\beta 2$-GP I).

Diagnostic ratios (Y) was calculated using variables include identifying informative indicators.

The first model is described by the equation (1):

$Y=\exp (-0,383+0,266 *$ auto-AB $\quad \mathrm{LuM}+0,062 * \mathrm{EPZs}) / 1+$ $\exp (-0,383+0,266 *$ auto-AB LuM + 0,062*EPZs $)$

$Y$ - diagnostic coefficient, -0,383 - constant, 0,266 и 0,062 - coefficients of predictors, EPZs - relative quantity of eosinophils in blood (\%); auto-AB LuM - relative contents auto-AT to membrane antigenes of a lung parenchyma (\%); $2 * \log ($ Likelihood $)=102,316, \chi 2=25,136, \mathrm{df}=2, \mathrm{p}=0,0000035$ (Fig. 1).

If $\mathrm{Y}$ is less than 0.5 did conclusion about the absence of the body's reaction to formaldehyde and predicted lack of sensitization of the organism to formaldehyde, with $\mathrm{Y}$ more than 0.5 have a reaction to formaldehyde is considered positive and predicted organism sensitization to formaldehyde. 
Next to verify the adequacy of the proposed method in a group of persons that are included and the ratio of the forecast is not included in the training group was calculated and the real outcome (there is a reaction on formaldehyde or not), is presented in Table 2 .

The sensitivity of the method was $59.52 \%$, specificity $90.00 \%$.
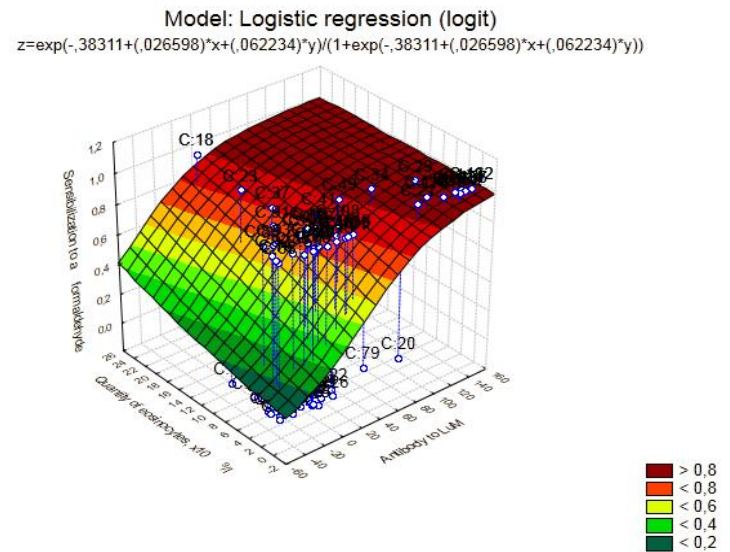

Fig. 1. Prediction model of sensitization to formaldehyde in adolescents with hematological and immunological parameters

TABLE 2 THE RATIO OF THE FORECAST AND THE ACTUAL DIAGNOSIS OF THE SURVEYED ADOLESCENTS USING THE MODEL OF HEMATOLOGICAL AND IMMUNOLOGICAL PARAMETERS

\begin{tabular}{|l|l|l|l|}
\hline \multirow{2}{*}{$\begin{array}{c}\text { Ranges design factor for } \\
\text { the forecast }\end{array}$} & \multicolumn{3}{|c|}{ Reaction of formaldehyde in LMIT } \\
\cline { 2 - 4 } & $\begin{array}{c}\text { Presence } \\
\text { (fact) }\end{array}$ & \multicolumn{1}{|c|}{$\begin{array}{c}\text { Absence } \\
\text { (fact) }\end{array}$} & \multicolumn{1}{|c|}{ Total } \\
\hline $\begin{array}{l}\text { Estimated coefficient Y } \\
\text { more than 0.5 } \\
\text { (Predicted response to } \\
\text { formaldehyde) }\end{array}$ & $\begin{array}{l}24 \text { persons } \\
(57.1 \%)\end{array}$ & $\begin{array}{l}18 \text { persons } \\
(42.9 \%)\end{array}$ & $\begin{array}{l}42 \\
\text { persons } \\
(100 \%)\end{array}$ \\
\hline $\begin{array}{l}\text { Estimated coefficient Y } \\
\text { less than 0.5 } \\
\text { (The reaction is not } \\
\text { expected to formaldehyde) }\end{array}$ & $\begin{array}{l}3 \text { persons } \\
(6.0 \%)\end{array}$ & $\begin{array}{l}47 \text { persons } \\
(94.0 \%)\end{array}$ & $\begin{array}{l}50 \text { persons } \\
(100 \%)\end{array}$ \\
\hline
\end{tabular}

The second model predicting sensitization of the organism adolescents to formaldehyde described by the equation (2):

$$
Y=\exp \left(-0,222+0,004^{*} \text { auto-AB } \beta 2-\mathrm{GP} \text { I }+0,026^{*}\right.
$$
auto-AB LuM $) /(1+\exp (-0,222+0,004 *$ auto-AB $\beta 2-\mathrm{GP}$ I $+0,026^{*}$ auto-AB LuM))

$Y$ - diagnostic coefficient, - 0,222 - constant, 0,004 и 0,026 - coefficients of predictors; auto-AB LuM - relative contents auto-AB to membrane antigenes of a lung parenchyma (\%); auto-AB to $\beta 2$-glycoprotein I ( $\beta 2$-GP I) - relative contents auto-AB to $\beta 2$-glycoprotein I ( $\beta 2$-GP I).

For this model $-2 * \log ($ Likelihood $)=101,7062$, $\chi 2=24,13378, \mathrm{df}=2, \mathrm{p}=0,0000058$ (fig. 2).

As in the case of the first model threshold value $\mathrm{Y}$ for predicting the presence or absence of sensitization to formaldehyde was 0.5 .

Evaluation of the sensitivity and specificity of the second model were very close in meaning to the first and amounted to $59.52 \%$ and $90.00 \%$, respectively (Table 3 ).
The data obtained show that under load is formed of manmade sensitization of the organism adolescents formaldehyde. Informative immunological and hematological parameters (eosinophils in the blood, the relative level of autoantibodies to membrane antigens lung parenchyma LuM and beta 2glycoprotein I $\beta 2-G P$ I) enabled the development of mathematical formulas, that allow forecast organism sensibilization Adolescents in groups studied by us to formaldehyde without applying LMIT. Both models developed by us have high specificity, but their disadvantage is low sensitivity. Despite this, these methods predict sensitization suitable for use in screening surveys of urban and rural population, as well as people in remote areas of health institutions and research organizations.

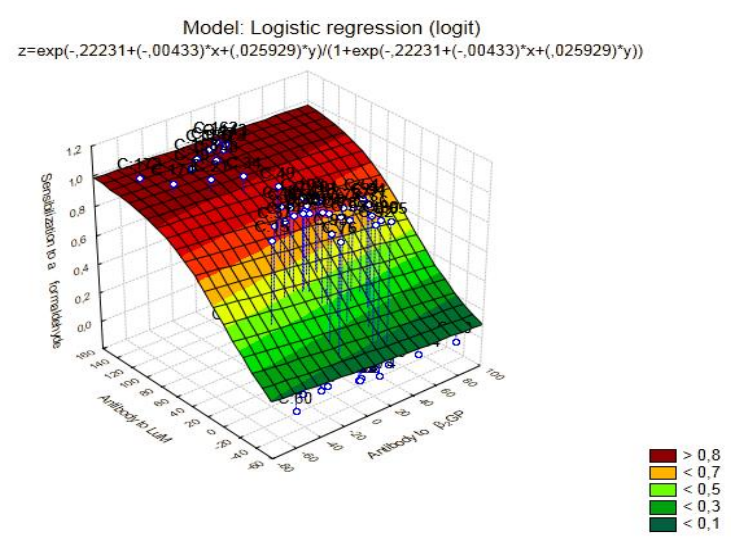

Fig. 2. Prediction model of sensitization to formaldehyde in adolescents with immunological parameters

TABLE 3 THE RATIO OF THE FORECAST AND THE ACTUAL DIAGNOSIS OF THE SURVEYED ADOLESCENTS USING IN THE MODEL AS PREDICTORS OF IMMUNOLOGICAL PARAMETERS MODEL

\begin{tabular}{|c|c|c|c|}
\hline \multirow{2}{*}{$\begin{array}{c}\text { Ranges design factor for } \\
\text { the forecast }\end{array}$} & \multicolumn{2}{|c|}{$\begin{array}{c}\text { Reaction of formaldehyde } \\
\text { in LMIT }\end{array}$} & \multirow{2}{*}{ Total } \\
\hline & $\begin{array}{l}\text { Presence } \\
\text { (fact) }\end{array}$ & $\begin{array}{c}\text { Absence } \\
\text { (fact) }\end{array}$ & \\
\hline $\begin{array}{l}\text { Estimated coefficient Y more } \\
\text { than } 0.5 \\
\text { (Predicted response to } \\
\text { formaldehyde) }\end{array}$ & $\begin{array}{c}25 \text { persons } \\
(59.5 \%)\end{array}$ & $\begin{array}{c}17 \text { persons } \\
(40.5 \%)\end{array}$ & $\begin{array}{l}42 \\
\text { persons } \\
(100 \%) \\
\end{array}$ \\
\hline $\begin{array}{l}\text { Estimated coefficient Y less } \\
\text { than } 0.5 \\
\text { (The reaction is not expected } \\
\text { to formaldehyde) }\end{array}$ & $\begin{array}{l}5 \text { persons } \\
(10.0 \%)\end{array}$ & $\begin{array}{l}45 \text { persons } \\
(90.0 \%)\end{array}$ & $\begin{array}{l}50 \\
\text { persons } \\
(100 \%)\end{array}$ \\
\hline
\end{tabular}

\section{CONCLUSION}

Presented in the article approach for predicting sensitization to formaldehyde in children, based on the statistical methods of data analysis, it allows its use for screening examinations. Prognostic approach allows for the most effective organization to help children, the preservation and strengthening of health. This forecast allows medical personnel to determine the risk of the existence and development of allergy pathology.

\section{REFERENCES}

[1] B.T. Velichkovskii, "Environmental pathology", Health service of RF, № 3, 1994, pp. 6-9. 
[2] I.V. Yatsyna, E.L. Sineva, A.V. Tulakin, I.Y. Zhadan, E.A. Preobrazhenskaya, E.O. Sarancha, "The health of children in the industrialized”, Gig. Sanit, vol. 94 (5), 2015, pp. 39-44.

[3] E.A. Abramatets, N.V. Efimova, "Some epidemiological aspect of allergopathology in teen-agers living in industrial centres", Siberian Medical Journal, vol. 105 (6), 2011, pp. 216-218.

[4] A.L. Vertkin, A.V. Dadykina, M.D. Lukashov, R.S. Gambarov, “Acute allergic diseases (diagnosis, treatment, typical mistakes)", The doctor, № 2, 2007, pp. 66-70.

[5] R.M. Haitov, N.I. Il'ina, "Allergic diseases in Russia at the turn of the century. Assessment of the situation in the XXI century", Bulletin of St. Petersburg State Medical Academy named after I.I. Mechnikov, № 1, 2005, pp. 170-176.

[6] K.A. Lebedev, I.D. Ponyakina, "Immunology of recognizing images (Integrated Immunology)”. M: «LIBROCOM», 2009, 256 p.

[7] N.V. Ovsyannikov, V.A. Lyapin, S.N. Avdeev, "Environmental pollution and the incidence bronchial asthma of the adult population of a large industrial city”, Kazan Medical Journal, № 4, 2011, pp. 577-581.

[8] N.M. Balabina, "Pollution of atmospheric air as a risk factor of formation iron deficiency anemias in adult urban population", Siberian medical journal, № 1, 2008, pp. 36-37.

[9] A.I. Borodin, E.M. Ovchinnikov, "Ecologo-economic problems of technogenic influence of pollution on disease of the population", Pharmoeconomics. Modern pharmacoeconomics and pharmacoepidemiology, vol. 5 (1), 2012, pp. 28-29.
[10] O.V. Tulyakova, "Effect of air pollution on morbidity and mental development features in children", Kursk scientific and practical bulletin "Man and his health", № 1, 2012, pp. 165-169.

[11] B.J. Kim, J.H Seo., Y.H. Jung, H.Y. Kim, J.W. Kwon, H.B. Kim, S.Y. Lee, K.S. Park, J. Yu, H.C. Kim, J.H. Leem, J.Y. Lee, J. Sakong, S.Y. Kim, C.G. Lee, D.M. Kang, M. Ha, Y.C. Hong, H.J. Kwon, S.J. Hong, "Air pollution interacts with past episodes of bronchiolitis in the development of asthma", Allergy, vol. 68 (4), 2013, pp. 517-523.

[12] V.B. Dorogova, N.A. Taranenko, O.A. Rychagova, "Environmental formaldehyde and its organism effects (survey)", Bulletin of the East Siberian Scientific Center SBRAMS, № 1 (71), 2010, pp. 32-35.

[13] Yu.D. Gubernskiy, N.V. Kalinina, E.B. Gaponova, "Hygienic characteristics of chemical air pollution in residential and public buildings". In: Materials of the Plenum of the Scientific Council of the Russian Federation for Human Ecology and Environmental Health «Methodological problems in the study, assessment and regulation of chemical pollution and its impact on public health». M.; 2015, pp. 102105.

[14] D.K. Novikov, Yu.V. Sergeev, P.D. Novikov, "Drug allergy". M: The National Academy of Mycology, 2001, 330 p.

[15] A.B. Poletayev, "New approaches to the early detection of pathological changes in the human body", Guidelines for doctors. M: «Immunkulus», 2011, 64 p. 